\title{
Middlemen: Good for Resources and Fishermen?
}

Pham Thi Thanh Thuy ${ }^{1 *}$, Ola Flaaten ${ }^{1}$, Anders Skonhoft ${ }^{2}$

${ }^{1}$ Norwegian College of Fishery Science, University of Troms $\emptyset$ - The Arctic University of Norway

${ }^{2}$ Department of Economics, Norwegian University of Science and Technology

*Corresponding author. Email: thanh.thuy@uit.no

\begin{abstract}
This paper studies the role of middlemen in open-access fisheries and how the organization of the supply chains affects resource exploitation and the level and distribution of economic rent. Imperfect competition among middlemen can help ensure that fish stocks are not depleted, as in the case of open-access fisheries and competitive markets. This also induce higher economic rent for the supply chain in total, from a fish price increase in the final market. The supply chains of inshore anchovy and offshore skipjack tuna fisheries in Vietnam are used as empirical examples. The results show that there is neither oligopsonistic nor monopsonistic power for the middlemen and that the anchovy stock is being overexploited. For the offshore skipjack tuna case, middlemen has oligopsony power in the negotiation and the stock is proved to be lower than the level that produces the maximum sustainable yield.
\end{abstract}

Key words Open access fishery, economic rent, prices, market power, middlemen. 


\section{Introduction}

In many developing countries, fisheries play a vital role in providing income, food and employment. However, the authorities have often little control over the activities. Due to high population growth and few alternative employment opportunities for the fishing population, this has resulted in overfishing in many coastal and ocean areas. The fishery is frequently of the open-access type, and the management problems can be traced back to Garrett Hardin's (1968) famous allegory of 'the tragedy of the commons'. In this paper, we draw attention to the organization of the fisheries supply chains in general and to the role of middlemen in particular, and we demonstrate that under certain conditions the presence of middlemen may reduce the degree of overfishing and contribute to economic rent creation.

Various solutions to the open-access fisheries problems have been proposed to remedy the market and management failure. One solution has emphasized the need for government regulation. To manage the resources, the authorities more or less have to define and enforce rules regarding participation, effort use, where and when fishing can take place, and how much can be fished. Taxes can be a part of the solution (Flaaten and Schulz, 2010, Flaaten, 2018). Another solution has been to introduce private property rights to fishing quotas. It is argued that by privatizing rights and making them transferable (ITQ's), incentives for overfishing will be removed (Hannesson, 2000). A third solution favors comanagement, which implies that different stakeholders should take a joint responsibility for managing the resources (Ostrom, 1990).

All three solutions can be difficult to implement, especially in developing countries. The governments may lack resources and capacity to set science-based quotas and to introduce effective measures to regulate fishing. Market-based solutions, such as fishing rights being auctioned off, also require significant monitoring, control and enforcement, and the social costs can be prohibitive high. Similarly, co-management rests on many institutional 
preconditions that are not present everywhere (Ostrom, 1990; 2009). This raises the question of whether there are other mechanisms that may contribute to sustainable development and combine the goals of resource conservation, economic efficiency and social equity.

It is well known that middlemen abound in the fish trade in many developing countries. Their efficiency and social role has been discussed for decades, and the opinions diverge. Some regard middlemen as purely exploitative and maintain that by bypassing the middlemen, the leakage of benefit would be reduced along the supply chain (Masters, 2008; Frandsen et al., 2009). Others point out that middlemen are indispensable and perform important functions, including selling fish to the processing industry, grading or processing fish themselves, and selling to the world market (Crona et al., 2010; Arya et al., 2015). Additionally, the middlemen reduce the time and effort needed by fishermen to marketing their products. In fact, the fishermen often cannot perform these tasks on their own due to limited education and knowledge in the fields of trade and negotiation. The fishermen may also rely on financial guarantees provided by the middlemen during fishing periods, notably in periods with low catches.

While acknowledging these functions, others again emphasize the power asymmetry between fishermen and middlemen. The fishermen offer a perishable good, and they have few alternative outlets. They also have limited information about prices, and they often have to accept the price offered by the buyers. Hence, the middlemen can strongly influence the ex-vessel price, the price that fishermen receive when selling their harvest, and the price in the downstream markets tends to be defined by the price in the upstream markets. Few studies, however, have elaborated on these relationships and analyzed the effects of market structure on resource exploitation and economic rent in fisheries (WTO, 2010).

In this paper, we take a new look at the role of middlemen as the intermediaries in the fisheries supply chains. What are the economic and biological effects of middlemen in the 
supply chains? Given that a first best solution may be unattainable, can the presence of middlemen with market power be a second best solution that may help to achieve a more sustainable management? According to second-best theory, a correction of a market imperfection in one area does not necessarily lead to an improvement in efficiency at the global level (Kronbak et al., 2014). For example, by removing the imperfection associated with the market power of middlemen, which hampers competition in the value chain, the fishing pressure might be increased. This indicates that it is necessary to study the situation and the implications of various measures more in detail. The role of middlemen is seldom accounted for in fisheries governance in developing countries. Three classical studies that discuss the linkage harvesting-processing sectors (Crutchfield and Pontecorvo, 1969; Clark and Munro, 1980; Schworm, 1983) all argue that monopsonistic processors may improve efficency of the utilization of a common pool resource. In this paper, we take the analysis one step further by explicitly incorporating the middlemen into the open-access model. The theoretical discussion considers various market structures in the intermediary level (competitive, oligopsony and monopsony), and also includes heterogeneous fishermen in the harvesting sector. Two case studies from Vietnam illustrate and confront the theoretical discussion.

The findings of the paper demonstrate that middlemen with market power can help protect marine resources from depletion by implicitly "taxing" the harvest, leading to lower ex-vessel price. Therefore, the problem of open-access fisheries, attracting too much fishing effort and dissipating resource rent, may be avoided, fully or partly, when middlemen with market power is included in the analysis. It transpires that intervention by the government is necessary only if this market power is too weak or too strong. The former may lead to excessive effort and the latter to underutilization of the fishery resources. 
The remainder of the paper is structured as follows. First, we formulates a basic model of the relationship between the final market price and the ex-vessel price, taking into account the degree of market power among middlemen. Next, the effects on the ex-vessel price, fish stock, and rents of fishermen and middlemen in the supply chain of a price change in the final market are analyzed. In following section, the theoretical findings are applied to two cases - the offshore skipjack tuna international (Thunnus albacares) and the inshore anchovy domestic (Stolephorus commersonnii, Stolephorus tri, Stolephorus indicus) supply chains in Vietnam. Finally, the main findings are discussed and summarized.

\section{The basic model}

The supply chain model links the final fish market and the ex-vessel market. Focusing on the export supply chain of developing countries, there are essentially three market segments that define this supply chain: the first stage market, the intermediary market, and the final stage market. Within this conceptualization, middlemen receive the final market price for the fish and then offer an ex-vessel price to fishermen. Thus, affected by the final market they are both part of an integrated chain of economic functions and linkages across geographic boundaries (Gudmundsson et al., 2006; Nielsen, 2006). The economic interests of fishermen and middlemen may differ, but ultimately their income depends on the consumers' willingness to pay for the fish. In this paper, the point of departure is a pure open-access fishery, which is common in many developing countries. Vessels are, by assumption, heterogeneous, as this is typical in most fisheries, and vessels may vary with respect to labour use and technological characteristics, such as size, engine power, and gear-type (Flaaten, 2018).

In what follows, the natural growth of the fish stock is given by the peak-valued Gompertz-Fox function. This model also yields a shape similar to the backward bending 
curve in fisheries (Thuy and Flaaten, 2013), and thus helps link fisheries trade and fish stock. The natural growth is hence defined by:

$G(X)=r X \ln \frac{K}{X}$

where $X$ is stock (measured as biomass), $r$ is the intrinsic growth rate and $K$ is the carrying capacity. The harvest is given by the standard Schaefer function:

$H=q E X$,

with $E$ as fishing effort, and $q$ as the productivity ('catchability') coefficient. In biological equilibrium, harvest equals natural growth, $H=G(X)$ or:

$$
H=r X \ln \frac{X}{K},
$$

and this yields $E=\frac{r}{q} \ln \frac{K}{X}$. With $P$ as the ex-vessel price of raw fish, the total revenue is:

$\operatorname{TR}(E)=P(H) H=P(H) q E X$.

Vessels are heterogeneous and we assume the aggregate cost function is increasing and convex (Clark 2007, p.163):

$T C(E)=\frac{\gamma}{2} E^{2}$,

where $\gamma$ is the marginal cost of effort parameter. In bioeconomic equilibrium under openaccess, the average revenue of effort equals the marginal cost of effort, $A R(E)=M C(E)$ (Copes 1972), which implies $P q X=\gamma E$. This yields:

$P=\frac{\gamma r}{X q^{2}} \ln \frac{K}{X}$

In addition, the ex-vessel market supply price elasticity is defined as $\varepsilon=\frac{\partial H}{\partial P} \cdot \frac{P}{H} \cdot \frac{\partial H}{\partial P}$ is found by taking the derivative of Eq. (3), $\frac{\partial H}{\partial P}=r\left(\ln \frac{K}{X}-1\right) \cdot \frac{\partial X}{\partial P}$. When next inserting $\frac{\partial X}{\partial P}$ from Eq.

(5), $\frac{\partial X}{\partial P}=-\frac{q^{2} X^{2}}{\gamma r\left(\ln \frac{K}{X}+1\right)}$, the supply elasticity reads 
$\varepsilon=-r\left(\ln \frac{K}{X}-1\right) \cdot \frac{q^{2} X^{2}}{\gamma r\left(\ln \frac{K}{X}+1\right)} \cdot \frac{\gamma r}{X q^{2}} \ln \frac{K}{X} \cdot \frac{1}{r X \ln \frac{K}{X}}=\frac{1-\ln \frac{K}{X}}{1+\ln \frac{K}{X}}$ It is observed that $\varepsilon>0$ for $>\frac{K}{e}$, $\varepsilon<0$ for $X<\frac{K}{e}$, and $\varepsilon=0$ for $X=X_{M S Y}=\frac{K}{e}\left(X_{M S Y}\right.$; the maximum sustainable yield stock).

The maximum sustainable harvest follows then as $H=H_{M S Y}=\frac{r K}{e}$.

Eq. (5) can be used to discuss the linkage between prices and biological effects from the fisheries trade. Prices might also affect fishermen's behaviour and hence their harvesting strategies. Therefore, it is true to say that Eq. (5) implicitly expresses the meaning of the supply backward bending curve in fisheries introduced by Copes (1970) (see Figure 1). In the short run, the supply of fish increases associated with the price, but in the long run which is the focus of this paper, it is constrained by the limited growth of the stock. If the fish price is "low", the incentive to fish is weak, few fish are caught, and the fish population is abundant and near its carrying capacity level. For a very low price, no fishing takes place due to the cost. For a moderate fish price, more effort is attracted into fishing, more fish is caught and the fish population reduced. For a very high fish price, still more effort goes into fishing, but fewer fish are caught due to the depleted stock. Consequently, supply decreases with increased price when $P>P_{M S Y}$.

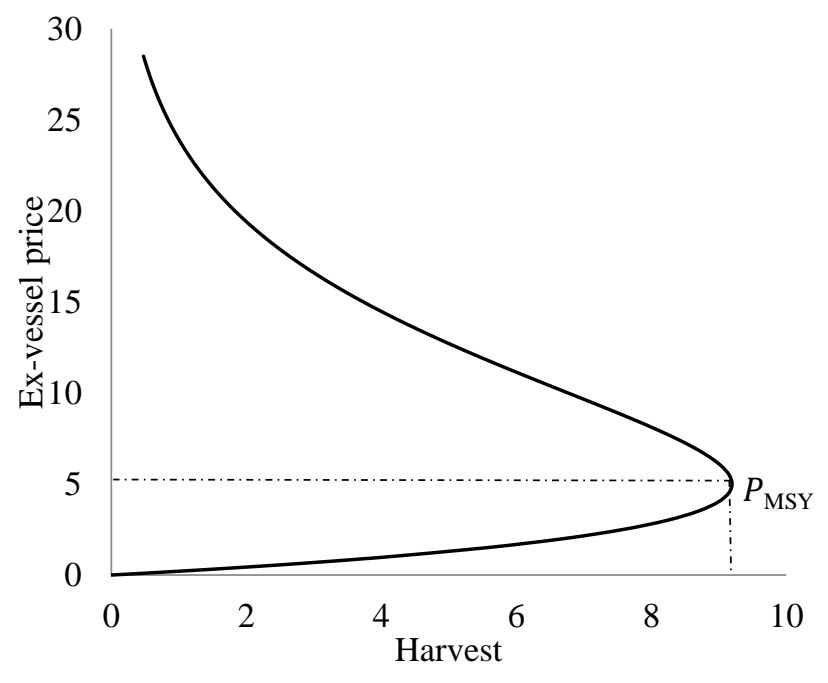

Figure 1: The backward-bending supply curve in fisheries

The profit of middleman $i$ is defined by the remainder of revenue after all operating costs: 
$\pi_{m}^{i}=\left(P_{n}-c^{i}-P(H)\right) h^{i}$,

where $P_{n}$ denotes the final market price of processed fish, $c^{i}$ is the average production cost per unit of processed fish, excluding the cost of raw fish, $h^{i}$ is the amount of raw fish bought by the middleman $i$. The conversion of raw fish to processed fish is assumed to be 1 .

The middleman's objective is to maximise profit, and the first order condition $\frac{d \pi_{m}^{i}}{d h^{i}}=$ 0 implies:

$P_{n}=P(H)+c^{i}+\frac{P(H)}{\frac{\partial H}{\partial P} \cdot \frac{P(H)}{H}} \cdot \frac{\partial H}{\partial h^{i}} \cdot \frac{h^{i}}{H}$

Assuming $n$ middlemen operating in the ex-vessel market, the total harvest bought in the exvessel market is accordingly $H=\sum_{i=1}^{n} h^{i}$. Rewriting Eq. (7) leads to the following simplified equation:

$P(H)=\frac{P_{n}-c^{i}}{1+\frac{\mu^{i}}{\varepsilon}} ; \varepsilon \neq 0$,

where the elasticity $\mu^{i}=\frac{\partial H}{\partial h^{i}} \cdot \frac{h^{i}}{H}$ indicates the market power for middleman $i$.

For simplicity, we now assume that the middlemen have identical cost structures, i.e., $c^{i}=c$ for all $i=1, \ldots, n$. Then $\mu^{i}$ will be similar for all the $n$ equally sized middlemen, $\mu^{i}=$ $\mu$, and the ex-vessel price $P$ can thus be expressed as follows:

$$
P(H)=\frac{P_{n}-c}{1+\frac{\mu}{\varepsilon}}
$$

The market power parameter is restricted as $0 \leq \mu \leq 1$. If $\mu=0$, the middlemen are perfect competitive. If $\mu=1$, there is only one monopsonistic middleman, whereas intermediate values of $\mu$ imply varying degrees of oligopsonistic competition.

With the above assumptions leading to Eq. (9), the ex-vessel price varies depending on the maximum affordable price that the middlemen can pay the fishermen, i.e., the final market price after deducting production costs, $P_{n}-c$, the degree of market power of the middlemen, $\mu$, and the price elasticity of supply, $\varepsilon$. 


\section{Final market price change effects}

Ex-vessel price

Based on the above theoretical model, we now focus on to what extent a final market price change is transmitted to the ex-vessel market. In this transmission, the role of market power of the middlemen is highlighted.

\section{Proposition 1}

1.1 An increase in the final market price implies an increase in the ex-vessel price, but the more market power the middlemen have, the less the increase will be; that is:

$$
\frac{\partial P}{\partial P_{n}}=\frac{1}{1+\frac{\mu}{\varepsilon}}>0 \text { and } \frac{\partial\left(\frac{\partial P}{\partial P_{n}}\right)}{\partial \mu}=-\frac{1}{\varepsilon\left(1+\frac{\mu}{\varepsilon}\right)^{2}}<0 .
$$

1.2 The price transmission between the final market and the ex-vessel market is perfect

$\left(\frac{\partial P}{\partial P_{n}}=1\right)$ under perfect competition $\mu=0$, and it is imperfect $\left(\frac{\partial P}{\partial P_{n}}<1\right)$ if competition is imperfect $0<\mu \leq 1$.

1.3 Middlemen with market power will keep the ex-vessel price below the level that produces $M S Y\left(P<P_{M S Y}\right)$.

Proof: See Appendix A.

Proposition 1.1 specifies the effect of the final market price and market power on the exvessel price. It is clear that as the final market price increases, the ex-vessel price increases as well. However, this increase is hampered by the middlemen's market power, and if the degree of market power is strong, a higher final market price will have less impact on the exvessel price.

Proposition 1.2 indicates that the proportionality of the ex-vessel price to the final market price depends on market power. When the middlemen remain competitive, i.e., when the middlemen have no market power, the final market price is transmitted perfectly to the 
ex-vessel price. In other words, a shift in the final market price is entirely reflected in the exvessel price. When the middlemen have market power, they are able to keep the price paid to the fishermen down, and thus the price transmission occurs imperfectly.

Proposition 1.3 is based on the rule that no middlemen will lose from export if market power prevails. They tend to offer a smaller ex-vessel price $P$ than the maximum affordable price, $P_{n}-c$. This keeps the ex-vessel price below the level that induces MSY.

\section{Fish stocks}

We next consider the effects of the final market price on the fish stock.

Proposition 2

2.1 An increase in the final market price implies a higher exploitation pressure, but the existence of middlemen with market power dampens the pressure on the stock; that is:

$$
\frac{\partial X}{\partial P_{n}}=-\frac{q^{2} X^{2}}{\gamma r\left(\ln \frac{K}{X}+1\right)} \cdot \frac{1}{1+\frac{\mu}{\varepsilon}}<0 \text { and } \frac{\partial\left(\frac{\partial X}{\partial P_{n}}\right)}{\partial \mu}=\frac{q^{2} X^{2}}{\gamma r\left(\ln \frac{K}{X}+1\right) \varepsilon\left(1+\frac{\mu}{\varepsilon}\right)^{2}}>0 \text {. }
$$

2.2 The negative fish stock effect is greater when the middlemen are competitive than when they are non-competitive: $\left.\frac{\partial X}{\partial P_{n}}\right|_{\mu=0}<\left.\frac{\partial X}{\partial P_{n}}\right|_{0<\mu \leq 1}<0$

2.3 Middlemen with market power will keep fish stocks above the level that produces MSY, while competing middlemen can deplete fish stocks below that of the MSY level: $\left(X>X_{M S Y}\right.$ for $0<\mu \leq 1 ; X<X_{M S Y}$ for $\left.\mu=0\right)$

Proof: See Appendix A.

Proposition 2.1 yields the impact of the final market price and the degree of market power among the middlemen on the equilibrium fish stock in the open-access fishery. When the final market price goes up, the middlemen offer a higher ex-vessel price to the fishermen. This motivates the fishermen to impose more fishing effort to obtain higher profit, again 
leading to a reduced fish stock. However, the market power has an offsetting influence. If imperfect competition exists, the reduction in fish abundance is smaller. As the degree of market power rises and the ex-vessel price falls, fishing is discouraged and the fish stock is preserved to a greater extent. This statement is also supported by Halsema and Withagen (2008).

Proposition 2.2 compares changes in the fish stock from a shift in the final market price under competitive market conditions and non-competitive market conditions at the intermediary level. It is clear that the pressure on the fish stock will be greater under perfect than under imperfect competition. A middleman with market power is able to reduce fish extraction. This is because, within certain limits, middlemen can decide how much to pay for raw fish. They tend to prefer a low ex-vessel price to save costs. From the fishermen's perspective, a low price discourages them from fishing, and some might stop fishing or even exit the fishery. Consequently, at equilibrium, a smaller fishing effort relieves pressure on the fish stocks.

Proposition 2.3 indicates how middlemen with and without market power encourage, or discourage fishermen from preserving resources. When perfect competition prevails, there is a race for fish among the middlemen and they are willing to pay a higher price to the fishermen to obtain more raw fish. A higher ex-vessel price encourages fishermen to intensify the harvesting pressure, ultimately leading to overexploitation of the fish stock. When the exvessel price rises above the level that yields MSY, a further price increase no longer provides the middlemen a larger supply of fish. Under imperfect competition, few middlemen are in the market and determine the ex-vessel price. They will set the price such that $P_{n}-c>P$, indicating that the offered price always is below the price that keep the stock above that of $X_{M S Y}$. 


\section{Economic rent}

Generally, economic rent is any payment to a factor of production in excess of the cost needed to bring that factor into production. In classical economics, economic rent is any payment made (including imputed value) or benefit received for non-produced inputs. In neoclassical economics, it also includes income gained by beneficiaries of other contrived exclusivity, such as labour guilds and corruption. When considering natural resources, the current economic rent equals the value of capital service flows rendered by the natural resources or their share in the gross operating surplus; its value is given by the value of extraction. In other words, it consists of two components: resource rent and intra-marginal rent. Under open-access fisheries, the resource rent is normally dissipated through excessive levels of fishing effort (Gordon, 1954; Hardin, 1968; Munro and Scott, 1985; Homans and Wilen 1997, 2005). However, intra-marginal rent still accrues to vessels that are more cost efficient than marginal ones. In other words, intra-marginal rent exists whenever vessels are heterogeneous in terms of capital and labour (Copes, 1972; Coglan and Pascoe, 1999; Duy et al., 2012b; Flaaten, 2018).

\section{Fishermen's rent}

The rent gained by the fishermen in the open-access fishery model, the intra-marginal rent, is defined by the revenue in excess of costs, and yields $\pi_{f}=P H-\frac{\gamma}{2}\left(\frac{H}{q X}\right)^{2}$ when using the cost function Eq. (4) and the harvest function Eq. (2). Substituting $H$ from Eq. (3) and $P$ from Eq. (5), and rearranging somewhat, gives:

$$
\pi_{f}=0.5 * P H=0.5 \frac{\gamma r^{2}}{q^{2}}\left(\ln \frac{K}{X}\right)^{2} .
$$


Therefore, to what extent the harvesting sector obtains rent depends not only on the cost parameter $\gamma$, but also on catchability $q$ and the stock size $X$, which in turn is influenced by fishermen's price $P$, and the carrying capacity $K$ and the intrinsic growth rate $r$.

\section{Middlemen's rent}

Following Eqs. (6) and (8), the maximised rent flow of a representative middleman can be expressed as $\pi_{m}^{i}=\frac{\mu^{i}}{\varepsilon} P h^{i}$. Noting that $H=\sum_{i=1}^{n} h^{i}$, the total rent of the intermediary sector is accordingly:

$\pi_{m}=\sum_{i=1}^{n} \frac{\mu^{i}}{\varepsilon} P h^{i}=\frac{\mu}{\varepsilon} P H=\frac{\mu}{\varepsilon} \frac{\gamma r^{2}}{q^{2}}\left(\ln \frac{K}{X}\right)^{2}$

Total rent

The total industry rent is found by summarizing Eqs. (10) and (11), which yields:

$\pi=\pi_{f}+\pi_{m}=\left(0.5+\frac{\mu}{\varepsilon}\right) P H=\left(0.5+\frac{\mu}{\varepsilon}\right) \frac{\gamma r^{2}}{q^{2}}\left(\ln \frac{K}{X}\right)^{2}$.

\section{Proposition 3}

3.1 Although there is no economic rent for the competitive middlemen, the fishermen still

gain a rent increase from a final market price increase; that is: $\frac{\partial \pi_{m}}{\partial P_{n}}=0$ and $\frac{\partial \pi_{f}}{\partial P_{n}}>0$

3.2 The existence of middlemen with market power generates higher rents for both fishermen and middlemen from a final market price increase; that is:

$\frac{\partial \pi_{f}}{\partial P_{n}}=\frac{1}{1+\frac{\mu}{\varepsilon}} \frac{r X \ln \frac{K}{X}}{\left(\ln \frac{K}{X}+1\right)}>0$ and $\frac{\partial \pi_{m}}{\partial P_{n}}=2 \frac{\mu}{\varepsilon+\mu} \frac{r X \ln \frac{K}{X}}{\left(\ln \frac{K}{X}+1\right)}>0$ with $\forall \varepsilon>0$

3.3 Middlemen with market power can partly transfer some rent from the fishermen to themselves; that is, when the degree of market power is higher, the fishermen will receive less rent and the middlemen will gain more rent: 
$\frac{\partial\left(\frac{\partial \pi_{f}}{\partial P_{n}}\right)}{\partial \mu}=-\frac{1}{\varepsilon\left(1+\frac{\mu}{\varepsilon}\right)^{2}} \frac{r X \ln \frac{K}{X}}{\left(\ln \frac{K}{X}+1\right)}<0 \quad$ and $\frac{\partial\left(\frac{\partial \pi_{m}}{\partial P_{n}}\right)}{\partial \mu}=\frac{2}{\varepsilon\left(1+\frac{\mu}{\varepsilon}\right)^{2}} \frac{r X \ln \frac{K}{X}}{\left(\ln \frac{K}{X}+1\right)}>0$

Total rent will also increase and more than in a perfect market:

$\frac{\partial\left(\frac{\partial \pi}{\partial P_{n}}\right)}{\partial \mu}=\frac{1}{\varepsilon\left(1+\frac{\mu}{\varepsilon}\right)^{2}} \frac{r X \ln \frac{K}{X}}{\left(\ln \frac{K}{X}+1\right)}>0 ;$ and $0<\left.\frac{\partial \pi}{\partial P_{n}}\right|_{\mu=0}<\left.\frac{\partial \pi}{\partial P_{n}}\right|_{0<\mu \leq 1}$

Proof: See Appendix A.

Proposition 3.1 shows that, in an overexploited fishery, the fishermen still gain more rent from a final market price increase, but the middlemen receive zero profit. High competition among the middlemen induce them to pay fishermen a higher price in order to purchase more fish. However, if the ex-vessel price becomes too high, some middlemen will sustain a loss and therefore leave the market; allowing the authors some reflections on the dynamics outside the equilibria. The same scenario also holds for the fishermen. In the early stage of overfishing, they stay in the market and continue fishing because they observe a relatively high price. Nevertheless, after a while, less fish is available and the harvest will eventually be reduced. Those fishermen who face a loss will stop fishing. However, the stock is not recovered to above that of the MSY level. The reason is that some cost efficient fishermen can stay and make profit even in the overexploited fishery.

Proposition 3.2 captures the importance of imperfect competition among the middlemen. When this is the case, increased final marketprices will be translated into higher rent for both the fishermen and the middlemen. With imperfect competition, the middlemen can control the ex-vessel price below and the stock above the levels that provide MSY. Thus, the effect of the final market price on the total economic rent of the fishermen and the middlemen are always greater than zero. 
While the presence of market power always promotes rent for the middlemen, it dissipates rent for the fishermen. Part of the fishermen's rent will be transferred to the middlemen, and this is pointed out in proposition 3.3. If there is no market power among the middlemen, the rent of the fishermen will be determined entirely by the shift in the ex-vessel price which in turn is equal to the shift in the final market price. If market power exists, increasing market power implies that the importance of the final market price is tempered; the rent of the fishermen drops and more accrues to the middlemen. The middlemen can collect the rents for themselves by keeping the price paid to the fishermen below the level that provides MSY. The total rents of the industry will be increased and can even become higher than those in the perfect market. However, most of the profits are captured by the middlemen.

\section{Examples}

To illustrate how the theoretical result may fit to reality, we consider two examples from Vietnamese fisheries: (1) the anchovy supply chain, in which anchovy is harvested by inshore purse seine vessels and supplied to the domestic market; and (2) the skipjack tuna supply chain, in which the skipjack tuna is provided by offshore gillnet fisheries for the international market. The characteristics of middlemen are different in these two supply chains; while processors are the key middlemen who bring skipjack tuna to the international market the anchovy arrives to the domestic market mainly through traders.

\section{The anchovy supply chain}

The anchovy supply chain is presented in Figure 2. Typically, all harvest is sold to middlemen before being transferred to final consumers. Middlemen here are defined as processing companies and/or traders. The first type of traders are those purchasing the harvest from several small fishing vessels at sea and selling the fish to the second type of traders 
operating on land. The latter provide fish for the processing companies and the domestic consumer market. The existence of the first type allows fishing vessels to stay at sea continuously for longer periods, thus, reducing fuel consumption and operating costs. The second type of traders normally have better equity financing than the first type, and can implement and negotiate larger transactions. These traders are usually better educated and qualified than fishermen and the first type of traders to deal with the many documents required when selling to the processing sector.

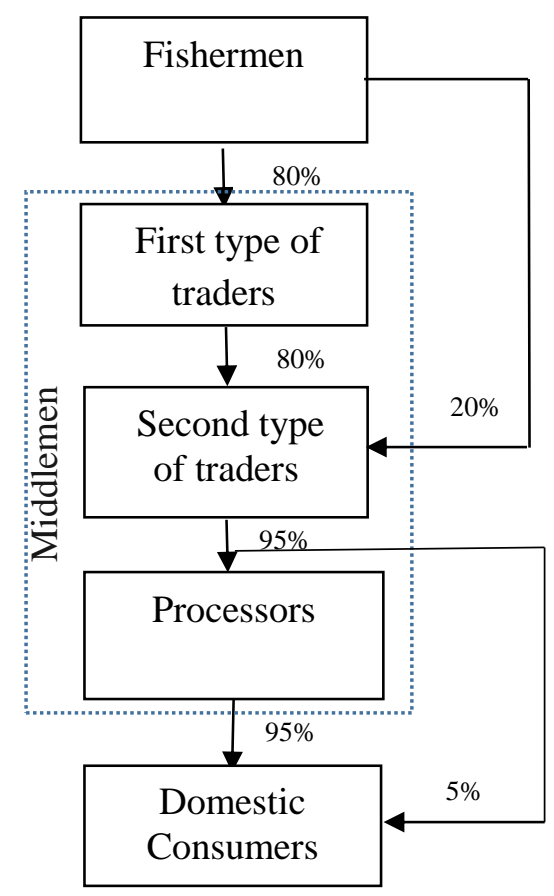

Figure 2: The anchovy supply chain in Vietnam

Source: Own data. Note: The percentages express percentage of anchovy quantity transmitted along the chain.

With varying domestic market price during the period 2005-2017, this example aims at illustrating what the estimated ex-vessel price, anchovy stock, and rent of the supply chain would be. Data includes actual ex-vessel prices and actual domestic market prices. These prices are all adjusted to the price level of 2017. Some parameter values are from three 
previous studies on anchovy fisheries in Vietnam; Thi et al. (2007), Tan (2015) and Thuy and Flaaten (2013) (see Table 1).

The estimation is achieved using numerical approaches. Particularly, we estimate the anchovy stock from Eq. (5), ex-vessel price from Eq. (8), and the rent from Eq. (10-12) (see details in Appendix B, Table B.1). The comparison between the actual prices and the estimated ones allows examination of the purchasing and market power of middlemen in the supply chain.

Table 1: Parameters for illustration of the anchovy supply chain case, 2005-2017

\begin{tabular}{cccl}
\hline Parameter & Unit & Value & \multicolumn{1}{c}{ Source } \\
\hline$K$ & Tonnes & 216,400 & Thi et al. (2007) \\
$r$ & & 1.03 & Thi et al. (2007) \\
$q$ & Tonnes per vessel year & 0.69 & Thi et al. $(2007)$ \\
$r$ & Million VND/ton/year ${ }^{(1)}$ & 9.21 & Thuy and Flaaten (2013) \\
$c$ & Million VND/ton/year & & \\
& & 9.00 & Tan (2015) \\
\hline
\end{tabular}

Note: ${ }^{(1)}$ The average cost of the years 2005, 2008, and 2011; ${ }^{(2)}$ The average cost for the period 2010-2015

The linkages between the domestic price and the ex-vessel price, the stock and the rent for the anchovy case are presented in Figures 3 and 4. Figures 3 a), c), d) show that with increasing domestic price, the ex-vessel price and the rent increase and the stock is reduced (as in Proposition 1.1, 2.1, and 3.1). Note that in the propositions the exogenous "final market" price changes, whereas in the anchovy case it is the "domestic market" price that is exogenous. The elasticity of supply is found to be negative for all the observed positive exvessel prices, implying that $\mu$ must be equal to zero (based on Eq. (8)). Thus, there is neither oligopsonistic nor monopsonistic power for the middlemen and that the anchovy stock is being overexploited (based on Proposition 2.3). The occurring of overfishing in the anchovy fishery has been established also by Thi et al. (2007) and Thuy and Flaaten (2013). Thus, 
middlemen gain no rent in this chain (based on Proposition 3). Furthermore, the estimated exvessel price is rather close to the actual one, indicating that the results derived from the model fit with reality (Figure 3b).

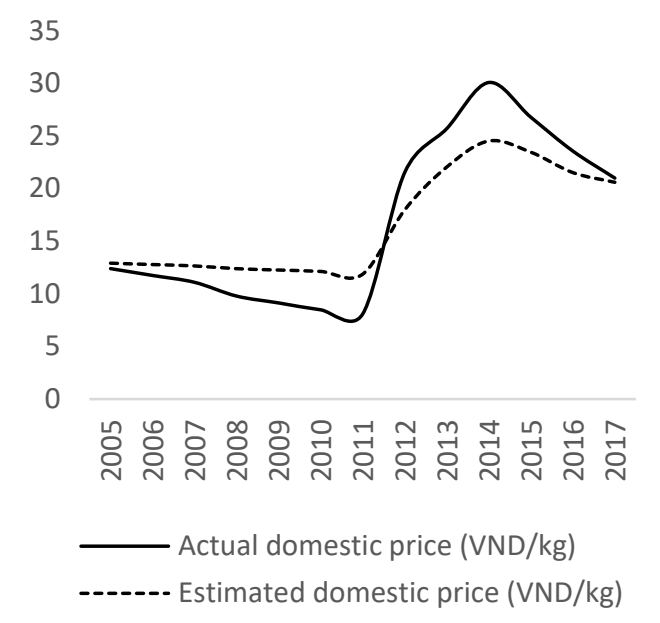

a)

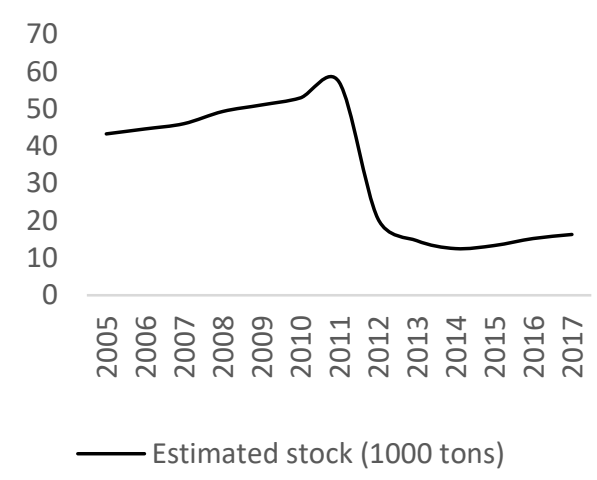

c)

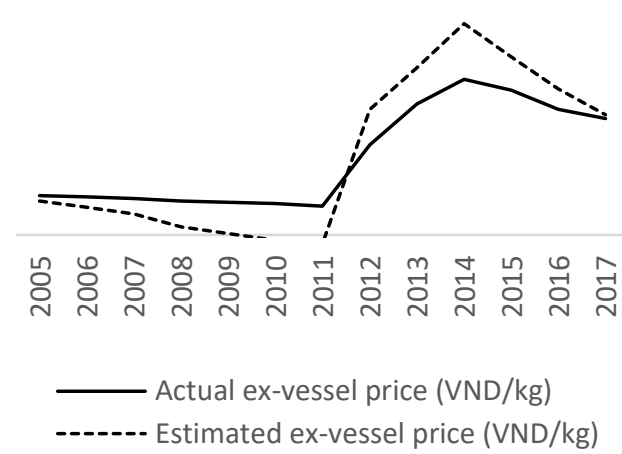

b)

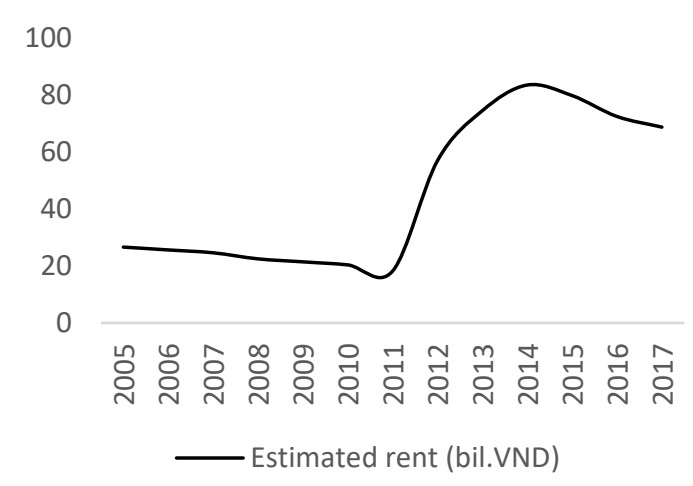

d)

Figure 3: Anchovy supply chain: a) Time path of actual domestic and estimated prices;

a) Time path of actual and estimated ex-vessel prices; c) Time path of estimated stock;

d) Time path of estimated rent 


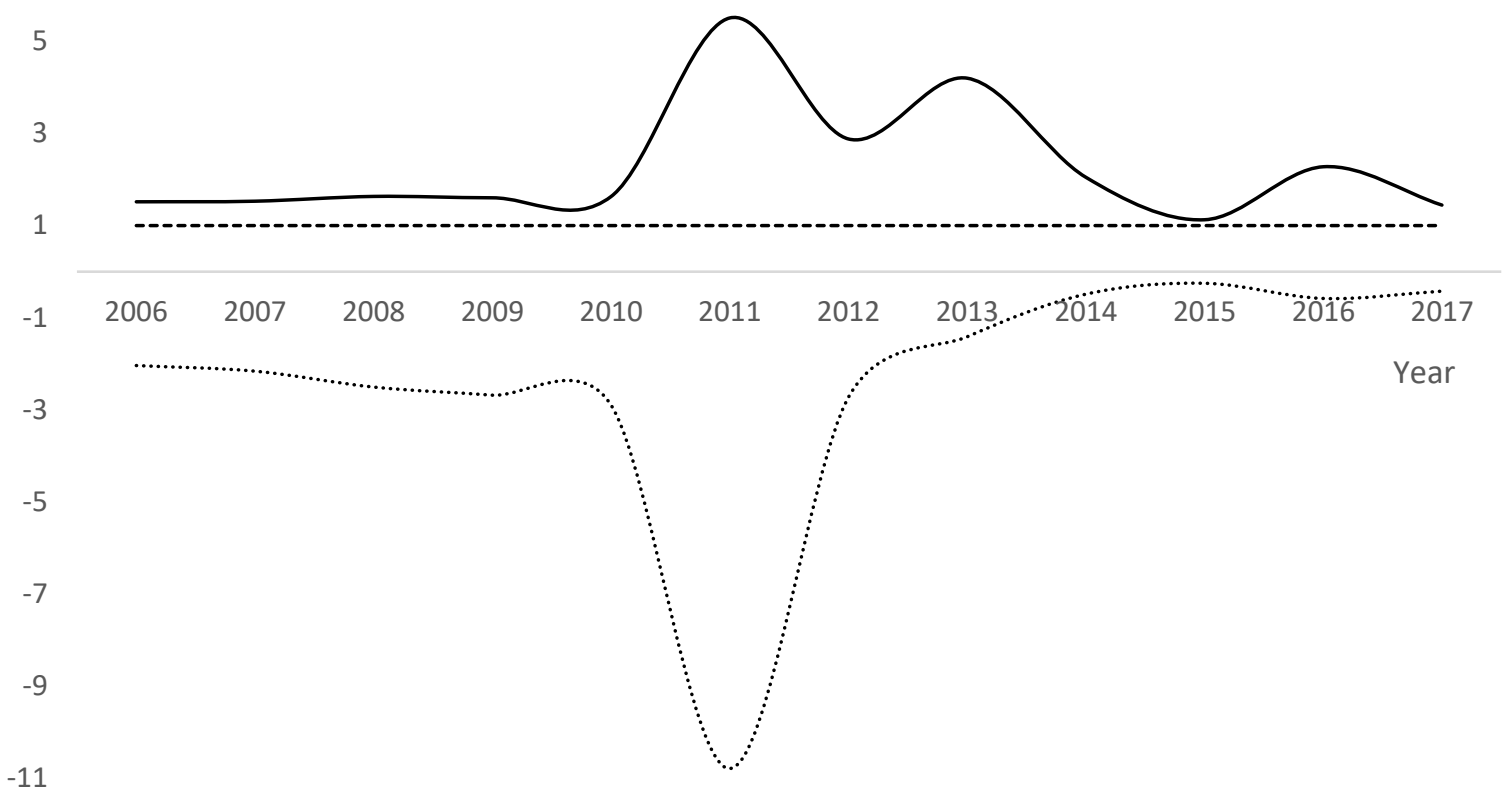

------- Marginal changes of estimated ex-vessel prices over actual domestic prices

Marginal changes of estimated stock over actual domestic prices

Marginal changes of estimated rents over actual domestic prices

Figure 4: Anchovy supply chain: Linkages between the domestic price and the ex-vessel price, the stock and the rent

The skipjack tuna supply chain

Like the anchovy supply chain, the skipjack tuna enters the final market through the contribution of two types of middlemen: processors and traders. However, traders in the offshore skipjack tuna fisheries are supplementary in linking the fishermen to the processing companies, to whom they sell almost all their fish. The supply chain of skipjack tuna is depicted in Figure 5. 
Middlemen

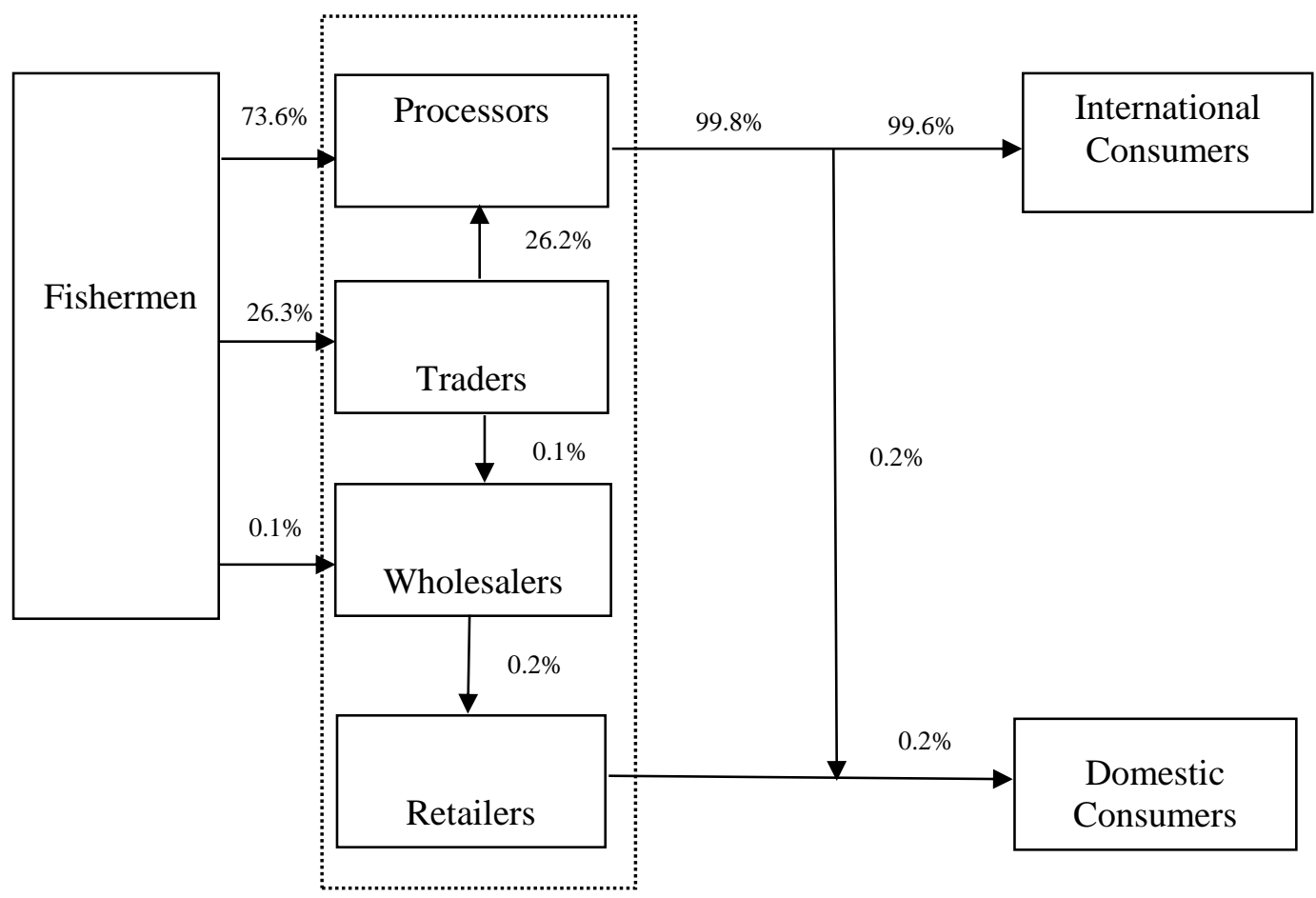

\section{Figure 5: The skipjack tuna supply chain in Vietnam}

Source: Duy et al. (2012a). Note: The percentages are of the skipjack tuna products transmitted along the chain.

There are several products included in the skipjack tuna supply chain. However, only the fresh fillet tuna ${ }^{1}$ is included in this analysis. We explore the effects of its export price on the ex-vessel price, and the stock. The market structure is also tested to identify if middlemen has any power adjusting prices in the chain. However, due to lack of data, the harvest data is used to discuss possible effects only on the stock, and the effects on the rent are not considered. The data were gathered from different sources, and quarterly data for the period 2009-2017 were used in the analysis.

\footnotetext{
${ }^{1}$ In value terms, the fresh fillets account for $80 \%$ of the total export.
} 
Figure 6 reveals that the ex-vessel price and the export price move quite closely up to 2011. However, later, the export price moved upward, then fluctuated from 2014, whereas the ex-vessel price stayed more or less constant. This indicates an asymmetric price transmission from the export price to the ex-vessel price. Indeed, an imperfect market structure is expected in the skipjack tuna supply chain, since the number of middlemen is relatively small compared to the number of fishermen. The quality of the skipjack tuna deteriorates soon after harvest. Therefore, middlemen may have some degree of market power over fishermen when the fishing ground - shore distance and time often force fishermen to sell their catch quickly. Furthermore, many fishermen are bound by credit arrangements and reciprocal agreements with the middlemen, adding to the oligopsonistic power of the middlemen.

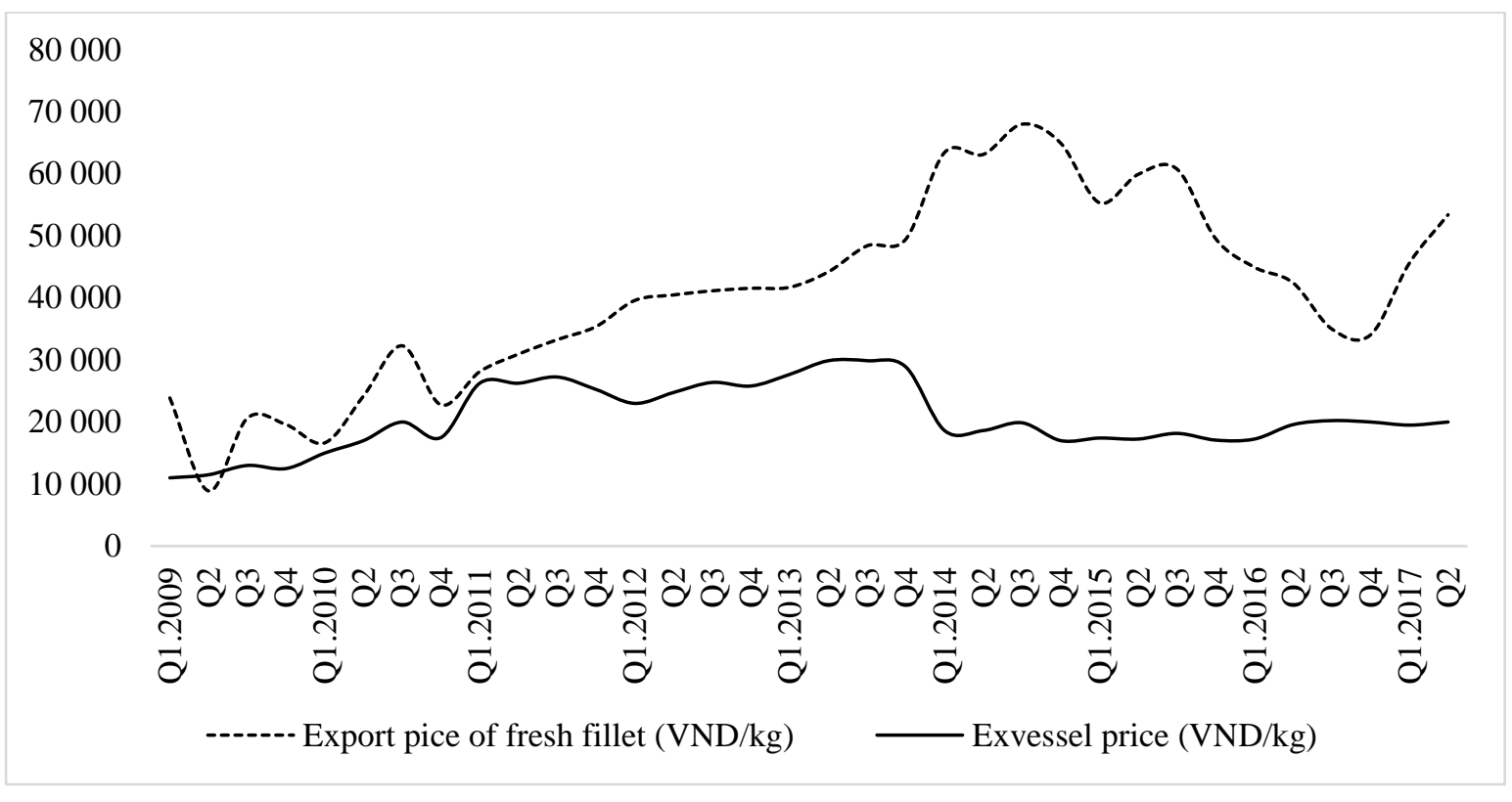

Figure 6: Fresh fillet tuna supply chain: Quarterly export price and ex-vessel price 2009-2017.

Source: Own data

Different techniques can be applied to examine price transmission in seafood commodity markets (Asche et al., 2002, 2007; Sapkota et al., 2015). The researcher's choice may depend on the questions asked, the data available and the assumptions to be made. The 
error correction model (ECM) is considered an appropriate specification for testing asymmetric price transmission. The ECM model employed is as follows:

$d\left(\ln P_{t}\right)=a_{0}+\sum_{i=1}^{n} a_{1 i} d\left(\ln P_{t-i}\right)+\sum_{j=1}^{n} a_{2 j} d\left(\ln P_{w, t-j}\right)+\delta u_{t-1}+\varepsilon_{t}$,

where $P_{t-i}$ and $P_{w, t-j}$ are the ex-vessel price and the export price of fresh fillet tuna at quarter $t-i$ and $t-j$, respectively, and $n$ is the lag order of $P_{w}$ and $P_{t}$. Furthermore, $d\left(\ln P_{t}\right)$ and $d\left(\ln P_{w, t-j}\right)$ represent their changes, measured on a quarterly basis, and $a_{0}$ is a constant term that capture transportation costs and quality differences. The estimated coefficient $a_{1 i}$ examines whether the ex-vessel prices from the past quarter(s) can have any impacts on that of the current period. The short-term price transmissions from $P_{w, t-j}$ to $P_{t}$ are measured by $a_{2 j}$. The transmission is either perfect or imperfect, depending on $a_{2 j}=1$ or $0<a_{2 j}<1$. $u_{t-1}$ is an error term, which implies speed of adjustment to long-term equilibrium while $\varepsilon_{t}$ is the residual (white noise).

Table 2: OLS parameter estimates of ECM

\begin{tabular}{lc}
\hline \multicolumn{1}{c}{ Variable } & Coefficient (standard error) \\
\hline$a_{0}$ & $-0.20(0.18)$ \\
$d\left(\ln P_{t-1}\right)$ & $-0.20(0.08)$ \\
$d\left(\ln P_{w, t-1}\right)$ & $-0.12^{*}(0.06)$ \\
$u_{t-1}$ & 0.24 \\
$R^{2}$ & 0.13 \\
Adjusted $R^{2}$ & $(1,-0.07)$ \\
Cointegration vector & \\
\hline S Significant at the 5\% level
\end{tabular}


The results of ECM model are given in Table $2^{2}$. The variable $d\left(\ln P_{w, t-1}\right)$ is insignificant at the $5 \%$ level, meaning that there was no short-term causality between the export price of fresh fillet and ex-vessel price of skipjack tuna. The coefficient of $u_{t-1}$ is negative $(-0.12)$ and significant. This shows that $12 \%$ of disequilibrium is corrected within one quarter for reaching a long-term equilibrium state. In other words, only $12 \%$ of the difference between long-term and short-term ex-vessel prices are adjusted within 3 months. More importantly, the estimated cointegration vector confirms that, given a $1 \%$ increase in the export price of the fresh fillet tuna, the ex-vessel price will increase by $0.07 \%$ in the long run; this implies that the export price leads the ex-vessel price, which is consistent with the fact that middlemen has a stronger position in negotiating prices. In short, market power prevails in the intermediary sector of the chain, and middlemen may abuse their market power to slow down an increase in ex-vessel price to reap their profit margin.

An interesting question is then if the stock is above the level that produces the MSY as claimed in Proposition 2.3. In fact, this seems to be true for the skipjack tuna case. The total catch of tuna has been recorded to increase substantially during the period 2010-2017 (Table 3). The figure is also evaluated as far below MSY (MARD, 2018). This indicates that tuna fishing is currently not overexploited and the stock is above that of the level that produces MSY.

Table 3: Total tuna catch in Vietnam's Exclusive Economic Zone 2010-2017

Unit: Metric tons

\begin{tabular}{cccc}
\hline Year & Skipjack tuna & Total tuna $^{3}$ & \% skipjack tuna/total tuna \\
\hline 2010 & 24,056 & 29,707 & 80.98 \\
2011 & 24,792 & 30,688 & 80.79
\end{tabular}

\footnotetext{
${ }^{2}$ The condition tests (ADF test and Johansen cointegration test) were satisfied before implementing ECM model. The results are available upon the request.

${ }^{3}$ Includes skipjack tuna, yellowfin tuna and bigeye tuna
} 


\begin{tabular}{lrrl}
2012 & 43,626 & 49,314 & 88.47 \\
2013 & 55,391 & 62,204 & 89.05 \\
2014 & 60,274 & 66,889 & 90.11 \\
2015 & 61,009 & 70,866 & 86.09 \\
2016 & 93,561 & 105,538 & 88.65 \\
2017 & 86,295 & 95,944 & 89.94 \\
\hline
\end{tabular}

Source: MARD (2018)

Recall, in short, the empirical results indicate that there is perfect competition among middlemen in the anchovy supply chain and that the anchovy stock is overexploited. In contrast, in the skipjack tuna supply chain, middlemen with their market power have contributed to keeping the stock above the MSY level.

\section{Discussion}

Our findings indicate that middlemen have the potential to contribute to resource sustainability, but are also part of the problem in the management of fisheries resources. They can partly offset overfishing caused by the open-access nature of the fishery, and they can assure that fishermen and middlemen share the rent increase when the final market price rises. At the same time, those with market power will take most of the rent.

The market power of middlemen has a similar effect as a harvest tax imposed on the fishermen. The government could, alternatively, have levied this, or as an export tax. It is clear that the implementation of a harvest tax requires management costs that are not free. The middlemen, who exist as a consequence of the functioning of the market, contribute to conservation of the fish stocks, and the government does not have to pay any fee for that. From a management point of view, this can be seen as an advantage, since management costs can make up a considerable percentage of landed value (Wallis and Flaaten, 2003). Furthermore, introducing the correct harvest tax to the fishermen is challenging. One question to ask is who receives the rents and who pays the costs. When an industry generates 
economic rent, there may be a race to capture the rent. In the bioeconomic models, it has usually been assumed that the rent accrues to the fishermen. However, rent could be captured by middlemen, as demonstrated above.

A market with a few powerful middlemen can also have some efficiency disadvantages. Fish stocks may be excessively conserved and not utilized in a rational economic way. Equality wise, middlemen may exploit their power and take most of the rent to the detriment of fishermen. Welfare economic optimum will not be achieved, since in this scenario the rent mainly accrues to a few middlemen. It is obviously that there are still tradeoffs and difficult balancing problems and this needs to be addressed by the authorities. Managing a limited number of middlemen or processors is probably easier and less costly than managing a large number of fishermen. Therefore, letting middlemen operate the market and capture the rent; then taxing them may be a second-best policy to apply. This study confirms that positive rent can be generated in open-access fisheries as intra-marginal rent, due to the heterogeneous cost of vessels. Both the number of vessels entering the fishery and their cost structure will determine the size of the rent. Fishermen stay in the fishery for the rent in relation to their opportunity costs that may include different types of social cost and their individual valuation of leisure time, and they stay in the fishery as long as the net benefit is positive. Of course, there may be dissimilarities between the short and long term. In the short term, it is sufficient that the vessels cover their operational costs, whereas in the long term vessels have to operate on a full-cost coverage basis. If the overall objective of the fisheries' policy is rent maximization, including resource rent and intra-marginal rent, the optimal sustainable yield may in some cases become closer to the MSY (Copes, 1972; Béné et al., 2010). This can be achieved by establishing an intermediary sector, consisting of middlemen with a moderate degree of market power. 
Different types of surplus can be generated in fisheries (Flaaten et al., 2017; Quaas et $a l ., 2018)$. The economic rent computed above consists of resource rent, intra-marginal rent and producer surplus in the harvest and the processing industries. The surplus to input owners are not discussed in this study since we focus on developing countries where input owners normally are operating in small-scale and hardly have any market power. The same applies to the retail sector in developing countries. However, in high income developed countries increasing market power of the modern retail sector seems to be the case, but this is outside the scope of this study.

The total cost function applied in this study is a simple polynomial function of degree two, which gives a linear marginal cost function. In fact, it could be generalized as a polynomial form with a degree greater than two, depending on how elastic the effort-cost relationship is. However, even though the mathematical results would be more complicated, the qualitative findings would in principle be the same.

In the real world, seafood supply chains tend to be more complex. They involve numerous interlinked activities performed by multiple intermediary actors located in different regions of a country, or even in various countries around the globe. Thus, to bring the theory closer to the real world, the analysis of the effects of the final market price on the basic biological and economic factors of open-access fisheries in a developing country, could take into account the diverse intermediaries and the complex supply chain.

\section{Conclusion}

From an economic efficiency point of view for Vietnam, it would be beneficial to prioritize management measures in the anchovy fisheries rather than in the tuna fisheries. The issue of rent creation in open-access fisheries has not received much scholarly attention. Rather, it has generally been assumed that the economic rent will dwindle as an inevitable consequence of 
the open-access characteristics. This study enriches the literature by addressing the possibility of positive rent in open access fisheries. It also identifies opportunities to enhance rent without overexploitation of fish stocks by organizing the intermediary market through middlemen with market power. Middlemen may play an important role and act as a functional equivalent to a harvest tax that help ensure resource conservation. However, unlike a harvest tax, which can be costly to implement, middlemen, as discussed above, operate as a constitutive part of the market. Nevertheless, too few middlemen is a problem when it comes to rent distribution to society. Even though middlemen can create more rents for the supply chain, these rents mainly benefit the middlemen. Hence, collecting tax from middlemen is important and could prove beneficial, since it is easier than including a large number of fishermen. The middlemen institution in the case of Vietnam, and probably also in many other countries, has developed through the functioning of the market without governmental participation. Letting middlemen operate the market, e.g. through licensing, and capture the rent -- then taxing them, could be a second-best policy to apply; however, this necessitates further research.

Appendix A. Proof of propositions

\section{Proof of Proposition 1}

To find the effect on the ex-vessel price of the final market price, we differentiate Eq. (10) which yields:

$$
\frac{\partial P}{\partial P_{n}}=\frac{1}{1+\frac{\mu}{\varepsilon}}
$$

We now consider how the ex-vessel price changes when market power appears. This is done by differentiating Eq. (A1) with respect to the degree of market power. This gives: 
$\frac{\partial\left(\frac{\partial P}{\partial P_{n}}\right)}{\partial \mu}=-\frac{1}{\varepsilon\left(1+\frac{\mu}{\varepsilon}\right)^{2}}$.

With $\mu=0$, Eq. (A1) yields $\frac{\partial P}{\partial P_{n}}=1$.

With $0<\mu \leq 1$, a middleman with market power will tend to offer a price at which $P_{n}-c>$ $P$. From this follows $\left(1+\frac{\mu}{\varepsilon}\right)>1 \rightarrow \frac{\mu}{\varepsilon}>0 \rightarrow \varepsilon>0$. This results in $\frac{\partial P}{\partial P_{n}}>0$, and $\frac{\partial\left(\frac{\partial P}{\partial P_{n}}\right)}{\partial \mu}>0$.

Thus, Eq. (A1) is always positive and Eq. (A2) is always negative; that is, satisfying Proposition 1.1.

With $\mu=0$, Eq. (A1) gives $\frac{\partial P}{\partial P_{n}}=1$; With $0<\mu \leq 1$, Eq. (A1) we find $\frac{\partial P}{\partial P_{n}}<1$.

Hence, Proposition 1.2 is proved.

A middleman with market power, $0<\mu \leq 1$, will tend to offer a price at which $P_{n}-c>P$. From this follows that $\varepsilon>0 \rightarrow X>\frac{K}{e}$ or $X>X_{M S Y}$ or $P<P_{M S Y}$. If middlemen are competitive, $\mu=0$, then $P_{n}-c=P$ with $\forall \varepsilon$. This condition is thus satisfied even if $\varepsilon<0$ or $P>P_{M S Y}$. Proposition 1.3 is proved.

\section{Proof of Proposition 2}

To see how fish stocks will be affected by opening up for trade, we use Eq. (5) and differentiate the fish stock with respect to the ex-vessel price:

$\frac{d X}{d P}=-\frac{q^{2} X^{2}}{\gamma r\left(\ln \frac{K}{X}+1\right)}<0$

Next, we multiply Eq. (A3) with Eq. (A1) in order to achieve the differential of fish stock with respect to the final market price. This yields:

$$
\frac{\partial X}{\partial P_{n}}=\frac{\partial X}{\partial P} \cdot \frac{\partial P}{\partial P_{n}}=-\frac{q^{2} X^{2}}{\gamma r\left(\ln \frac{K}{X}+1\right)} \cdot \frac{1}{1+\frac{\mu}{\varepsilon}}<0
$$


The effect of the degree of market power at the intermediary level on the fish stock is then found as:

$\frac{\partial\left(\frac{\partial X}{\partial P_{n}}\right)}{\partial \mu}=\frac{-q^{2} X^{2}}{\gamma r\left(\ln \frac{K}{X}+1\right)} \cdot \frac{-1}{\varepsilon\left(1+\frac{\mu}{\varepsilon}\right)^{2}}=\frac{q^{2} X^{2}}{\gamma r\left(\ln \frac{K}{X}+1\right) \varepsilon\left(1+\frac{\mu}{\varepsilon}\right)^{2}}>0$.

Hence, Proposition 2.1 is proved.

To prove Proposition 2.2, we consider the effects on the stock of an increase in the final market price with market failures, $\left.\frac{\partial X}{\partial P_{n}}\right|_{0<\mu \leq 1}$, and without market failures, $\left.\frac{\partial X}{\partial P_{n}}\right|_{\mu=0}$, at the intermediary level:

$\left.\frac{\partial X}{\partial P_{n}}\right|_{\mu=0}=-\frac{q^{2} X^{2}}{\gamma r\left(\ln \frac{K}{X}+1\right)}$

$\left.\frac{\partial X}{\partial P_{n}}\right|_{0<\mu \leq 1}=-\frac{q^{2} X^{2}}{\gamma r\left(\ln \frac{K}{X}+1\right)} \cdot \frac{1}{1+\frac{\mu}{\varepsilon}}$

$\left.\rightarrow \frac{\partial X}{\partial P_{n}}\right|_{\mu=0}<\left.\frac{\partial X}{\partial P_{n}}\right|_{0<\mu \leq 1}$

Proposition 2.2 is proved.

When $1 \geq \mu>0 \rightarrow P<P_{M S Y} \rightarrow E<E_{M S Y} \rightarrow X>X_{M S Y}$; When $\mu=0 \rightarrow P>P_{M S Y} \rightarrow E>$ $E_{M S Y} \rightarrow X<X_{M S Y}$. Proposition 2.3 is proved.

\section{Proof of Proposition 3}

To prove Proposition 3.1, we first differentiate $\pi_{f}$ with respect to $X$ in Eq. (11) to identify how the fishermen's rent changes in response to the stock:

$\frac{\partial \pi_{f}}{\partial X}=\frac{\gamma r^{2}}{q^{2}} \ln \frac{K}{X}\left(-\frac{1}{X}\right)<0$

Multiplying Eq. (A4) by Eq. (A5), the effect on fishermen's rent of the final market price is obtained:

$\frac{\partial \pi_{f}}{\partial P_{n}}=\frac{\partial \pi_{f}}{\partial X} \cdot \frac{\partial X}{\partial P_{n}}$ 
$\frac{\partial \pi_{f}}{\partial P_{n}}=\frac{\gamma r^{2}}{q^{2}} \ln \frac{K}{X}\left(-\frac{1}{X}\right) \cdot\left(-\frac{q^{2} X^{2}}{\gamma r\left(\ln \frac{K}{X}+1\right)} \frac{1}{1+\frac{\mu}{\varepsilon}}\right)=\frac{1}{1+\frac{\mu}{\varepsilon}} \frac{r X \ln \frac{K}{X}}{\left(\ln \frac{K}{X}+1\right)}>0$

Secondly, we consider how profit of the middlemen will be affected by opening up for trade.

Differentiating $\pi_{m}$ with respect to $X$ by using Eq. (12) yields then:

$\frac{\partial \pi_{m}}{\partial X}=2 \frac{\mu}{\varepsilon} \frac{\gamma r^{2}}{q^{2}} \ln \frac{K}{X}\left(-\frac{1}{X}\right)<0$

The effect on profit of the middlemen as a result of final market price changes is found by multiplying Eq. (A7) by Eq. (A4):

$\frac{\partial \pi_{m}}{\partial P_{n}}=\frac{\partial \pi_{m}}{\partial X} \cdot \frac{\partial X}{\partial P_{n}}$

$\frac{\partial \pi_{m}}{\partial P_{n}}=2 \frac{\mu}{\varepsilon} \frac{\gamma r^{2}}{q^{2}} \ln \frac{K}{X}\left(-\frac{1}{X}\right) \cdot\left(-\frac{q^{2} X^{2}}{\gamma r\left(\ln \frac{K}{X}+1\right)} \frac{1}{1+\frac{\mu}{\varepsilon}}\right)=2 \frac{\mu}{\varepsilon} \frac{1}{1+\frac{\mu}{\varepsilon}} \frac{r X \ln \frac{K}{X}}{\left(\ln \frac{K}{X}+1\right)}>0$ with $\forall \varepsilon>0$

The total rent effect is then:

$\frac{\partial \pi}{\partial P_{n}}=\frac{\partial \pi_{m}}{\partial P_{n}}+\frac{\partial \pi_{f}}{\partial P_{n}}=2 \frac{\mu}{\varepsilon} \frac{1}{1+\frac{\mu}{\varepsilon}} \frac{r X \ln \frac{K}{X}}{\left(\ln \frac{K}{X}+1\right)}+\frac{1}{1+\frac{\mu}{\varepsilon}} \frac{r X \ln \frac{K}{X}}{\left(\ln \frac{K}{X}+1\right)}$

$=\frac{2 \frac{\mu}{\varepsilon}+1}{\frac{\mu}{\varepsilon}+1} \frac{r X \ln \frac{K}{X}}{\left(\ln \frac{K}{X}+1\right)}>0$ with $\forall \varepsilon>0$

Propositions 3.1 and 3.2 are proved.

To show that the total rent of the supply chain are influenced by the degree of market power among middlemen, we differentiate Eq. (A6), Eq. (A8) and Eq. (A9) once more with respect to $\mu$ :

$\frac{\partial\left(\frac{\partial \pi_{f}}{\partial P_{n}}\right)}{\partial \mu}=-\frac{1}{\varepsilon\left(1+\frac{\mu}{\varepsilon}\right)^{2}} \frac{r X \ln \frac{K}{X}}{\left(\ln \frac{K}{X}+1\right)}$
$\frac{\partial\left(\frac{\partial \pi_{m}}{\partial P_{n}}\right)}{\partial \mu}=\frac{2}{\varepsilon\left(1+\frac{\mu}{\varepsilon}\right)^{2}} \frac{r X \ln \frac{K}{X}}{\left(\ln \frac{K}{X}+1\right)}$
$\frac{\partial\left(\frac{\partial \pi}{\partial P_{n}}\right)}{\partial \mu}=\frac{\partial\left(\frac{\partial \pi_{f}}{\partial P_{n}}\right)}{\partial \mu}+\frac{\partial\left(\frac{\partial \pi_{m}}{\partial P_{n}}\right)}{\partial \mu}=\frac{1}{\varepsilon\left(1+\frac{\mu}{\varepsilon}\right)^{2}} \frac{r X \ln \frac{K}{X}}{\left(\ln \frac{K}{X}+1\right)}$
$\varepsilon>0 \rightarrow \frac{\partial\left(\frac{\partial \pi_{f}}{\partial P_{n}}\right)}{\partial \mu}<0$ but $\frac{\partial\left(\frac{\partial \pi_{m}}{\partial P_{n}}\right)}{\partial \mu}>0$ and $\frac{\partial\left(\frac{\partial \pi}{\partial P_{n}}\right)}{\partial \mu}>0$ 
$\left.\frac{\partial \pi}{\partial P_{n}}\right|_{\mu=0}=\frac{r X \ln \frac{K}{X}}{\left(\ln \frac{K}{X}+1\right)}$

$\left.\frac{\partial \pi}{\partial P_{n}}\right|_{0<\mu \leq 1}=\frac{2 \frac{\mu}{\varepsilon}+1}{\frac{\mu}{\varepsilon}+1} \frac{r X \ln \frac{K}{X}}{\left(\ln \frac{K}{X}+1\right)}>\frac{r X \ln \frac{K}{X}}{\left(\ln \frac{K}{X}+1\right)}=\left.\frac{\partial \pi}{\partial P_{n}}\right|_{\mu=0}$ since $\frac{2 \frac{\mu}{\varepsilon}+1}{\frac{\mu}{\varepsilon}+1}>1$

Proposition 3.3 is proved.

\section{Appendix B.}

Table B.1: Anchovy supply chain: Summary of estimated domestic price, stock and rent

\begin{tabular}{ccccccccccccc}
\hline$P_{d}^{a}$ & $P_{d}^{e}$ & $P^{a}$ & $P^{e}$ & $\varepsilon$ & $X$ & $\pi_{f}$ & $\pi_{m}$ & $\pi_{m+f}$ & $\frac{\partial P_{d}^{e}}{\partial P_{d}}$ & $\frac{\partial X}{\partial P_{d}}$ & $\frac{\partial \pi}{\partial P_{d}}\left(\frac{\partial \pi_{f}}{\partial P_{d}}\right)$ & $\frac{\partial P^{a}}{\partial P_{d}}$ \\
\hline 12.40 & 12.92 & 3.92 & 3,40 & -0.23 & 43.30 & 26.58 & 0 & 26.58 & & & & \\
11.75 & 12.79 & 3.79 & 2,75 & -0.22 & 44.63 & 25.59 & 0 & 25.59 & 1,00 & $-2,04$ & 1,52 & 0,20 \\
11.10 & 12.66 & 3.66 & 2,10 & -0.21 & 46.04 & 24.59 & 0 & 24.59 & 1,00 & $-2,16$ & 1,53 & 0,20 \\
9.79 & 12.39 & 3.39 & 0,79 & -0.19 & 49.31 & 22.46 & 0 & 22.46 & 1,00 & $-2,51$ & 1,63 & 0,20 \\
9.14 & 12.26 & 3.26 & 0,14 & -0.18 & 51.06 & 21.41 & 0 & 21.41 & 1,00 & $-2,68$ & 1,60 & 0,20 \\
8.48 & 12.13 & 3.13 & $-0,52$ & -0.17 & 52.95 & 20.35 & 0 & 20.35 & 1,00 & $-2,90$ & 1,63 & 0,20 \\
8.09 & 11.87 & 2.87 & $-0,91$ & -0.14 & 57.21 & 18.17 & 0 & 18.17 & 1,00 & $-10,79$ & 5,51 & 0,66 \\
21.54 & 17.98 & 8.98 & 12,54 & -0.40 & 20.55 & 56.90 & 0 & 56.90 & 1,00 & $-2,73$ & 2,88 & 0,45 \\
25.70 & 22.05 & 13.05 & 16,70 & -0.46 & 14.66 & 74.40 & 0 & 56.90 & 1,00 & $-1,41$ & 4,20 & 0,98 \\
30.09 & 24.53 & 15.53 & 21,09 & -0.48 & 12.52 & 83.37 & 0 & 74.40 & 1,00 & $-0,49$ & 2,05 & 0,56 \\
26.79 & 23.47 & 14.47 & 17,79 & -0.47 & 13.35 & 79.66 & 0 & 83.37 & 1,00 & $-0,25$ & 1,13 & 0,32 \\
23.57 & 21.52 & 12.52 & 14,57 & -0.45 & 15.22 & 72.34 & 0 & 79.66 & 1,00 & $-0,58$ & 2,28 & 0,60 \\
21.00 & 20.60 & 11.60 & 12,00 & -0.44 & 16.31 & 68.62 & 0 & 72.34 & 1,00 & $-0,42$ & 1,45 & 0,36 \\
\hline
\end{tabular}

Note: $P_{d}^{a}$ is actual domestic price; $P_{d}^{e}$ is estimated domestic price; $P^{a}$ is actual ex-vessel price; $P^{e}$ is estimated ex-vessel price.

\section{References}

Asche, F., O. Flaaten, J.R. Isaksen and T. Vassdal (2002) 'Derived demand and relationships between prices at different levels in the value chain: a note'. Journal of Agricultural Economics, 53: 101-107

Asche, F., S. Jaffry, \& J. Hartmann (2007) 'Price transmission and market integration: vertical and horizontal price linkages for salmon'. Applied Economics 39(19):2535-2545 
Arya, A., C. Loffler, B. Mittendorf, T. Pfeiffer (2015) 'The middleman as a panacea for supply chain coordination problems', European Journal of Operational Research 240(2): $393-400$

Béné, C., B. Hersoug, E.H. Allison (2010) 'Not by rent alone: analyzing the pro-poor functions of small-scale fisheries in developing countries', Development Policy Review $28: 325-358$

Clark, C.W., G.R. Munro (1980) 'Fisheries and the processing sector: some implications for management policy', The Bell Journal of Economics 11:603-616

Clark, C.W. (2007) The Worldwide Crisis in Fisheries Economic Models and Human Behavior: Cambridge University Press.

Coglan, L., S. Pascoe (1999) 'Separating resource rents from intra-marginal rents in fisheries economic survey data', Agricultural Resource Economics Review 28:219-228

Copes, P. (1970) 'The backward-bending supply curve of the fishing industry', Scottish Journal Political Economy 17:69-77

Copes, P. (1972) 'Factor rents, sole ownership and the optimum level of fisheries exploitation', Manchester School of Economic and Social Studies 40:145-163

Crona, B., M. Nyström, C. Folke, N. Jiddawi. (2010) 'Middlemen, a critical social-ecological link in coastal communities of Kenya and Zanzibar', Marine Policy 34(4): 761-771

Crutchfield, J.A., G. Pontecorvo (1969) The Pacific salmon fishery: a study of irrational conservation, John Hopkins Press, Baltimore

Duy, N.N., N.T. Kim Anh, N.T. Tram Anh (2012) 'Balancing benefits between fishermen and actors in supply chains of capture fish products: the case of skipjack tuna in Khanh Hoa'. Science and Technology Journal of Agriculture and Rural Development 6: 11-19. Ministry of Agriculture and Rural Development, Vietnam 
Duy, N.N., O. Flaaten, N.T. Kim Anh. Q.K.T. Ngoc (2012) 'Open-access fishing rent and efficiency - The case of gillnet vessels in Nha Trang, Vietnam', Fisheries Research (127128): $98-108$

Frandsen, S., A. Kuyvenhoven, J., V. Braun. (2009) Case Studies in Food Policy for Developing Countries: Domestic Policies for Markets, Production, and Environment (Andersen P. \& Cheng F., Eds.). Cornell University Press. Retrieved from http://www.jstor.org/stable/10.7591/j.cttq45vz

Flaaten, O. (2018) Fisheries economics and management, $2^{\text {nd }}$ Edition. The Norwegian College of Fishery Science, University of Troms $\varnothing$, Troms $\varnothing$, ISBN 978-82-8266-026-6 "http://www.maremacentre.com/bioeconomics"

Flaaten, O., C.E. Schulz (2010) 'Triple win for trade in renewable resource goods by use of export taxes', Ecological Economics 69:1076-1082

Flaaten, O., K. Heen, T. Matthíasson (2017) ‘Profit and Resource Rent in Fisheries', Marine Resource Economics 32(3): 311-328.

Gordon, H.S. (1954) 'The economic theory of a common property resource: the fishery', Journal of Political Economy 62:124-142

Gudmundsson, E., F. Asche, M. Nielsen (2006) 'Revenue distribution through the seafood chain', FAO Fisheries Circular. No. 1019, [Available at] http://www.fao.org/docrep/009/a0564e/a0564e00.htm

Hannesson, R. (2000) 'Renewable resources and the gains from trade', Canadian Journal of Economics 33:122-132

Hardin, G. (1968) 'The tragedy of the commons', Science 162:16-30

Halsema, A., C. Withagen (2008) 'Managing multiple fishery pools: property rights regimes and market structures', Environment and Development Economics 13:775-794 
Homans, F.R., J.E. Wilen (1997) 'A model of regulated open access resource use'. Journal of Environmental Economics and Management 32:1-21

Homans, F.R., J.J. Wilen (2005) 'Markets and rent dissipation in regulated open access fisheries', Journal of Environmental Economics and Management 49:381-404

Kronbak, L.G., Squires, D., Vestergaard, N (2014) 'Recent developments in fisheries economics research.' International Review of Environmental and Resource Economics 7(1): $67-108$

MARD (2018) 'Annual report to the western and central pacific fisheries commission (WCPEC). Part 1: Information on fisheries, research, and statistics', Ministry of Agriculture and Rural Development, Hanoi, Vietnam.

Masters, A. (2008) 'Unpleasant middlemen', Journal of Economic Behavior \& Organization $68: 73-86$

Munro, G.R., A.D. Scott (1985) The economics of fisheries management. In: Knesse AV and Sweeney JL (eds.) Handbook of natural resource and energy economics, vol 2: Elsevier, Amsterdam, pp. 623-676

Ostrom, E (1990). Governing the Commons: The Evolution of Institutions for Collective Action. Cambridge: Cambridge University Press.

Ostrom, E (2009). A general framework for analyzing sustainability of social-ecological systems. Science 325 (5939): 419-422.

Nielsen, M. (2006) 'Trade liberalisation, resource sustainability and welfare: the case of East Baltic cod', Ecological Economics 58: 650-664

Quaas, Martin F., M.T. Stoeven, B. Klauere, T. Petersen, J. Schiller (2018) 'Windows of opportunity for sustainable fisheries management: the case of Eastern Baltic cod.' Environmental and Resource Economics 70(2): 323-341. 
Sapkota, P., M.M. Dey, Md. F. Alam, K. Singh (2015) 'Price Transmission Relationships along the Seafood Value Chain in Bangladesh: Aquaculture and Capture Fisheries', Aquaculture Economics \& Management, 19(1):82-103

Schworm, W.E. (1983) 'Monopsonistic control of a common property renewable resource', Canadian Journal of Economics 16:275-287

Tan PN (2015) 'Analysis of anchovy value chain in Khanh Hoa province'. [In Vietnamese: Phân tích chuỗi giá trị cá cơm tỉnh Khánh Hòa]. Master thesis, Nha Trang University: Nha Trang, Vietnam

Thi, D.V., N.K. Bat, D.V. Nguyen, P.V. Anh, N.V. Nghia, V.V. Ha, ... N.D. Thanh (2007) 'Anchovy stock assessment in southwest Vietnam, and the solutions for sustainable management'[In Vietnamese: Đánh giá nguồn lợi cá Cơm (Stolephorus spp.) ở vùng biển Tây Nam Bộ và đề xuất các giải pháp bảo vệ, khai thác hợp lý], Research Institute of Marine Fisheries: Hai Phong, Vietnam

Thurman, W.N., E.E. Jr. James. (1992) 'Valuing changes in commercial fishery harvests: a general equilibrium derived demand analysis.' Journal of Environmental Economics and Management 22(3):226-240

Thuy, T.T.P., O. Flaaten (2013) 'The backward-bending supply curve revisited', Journal of Sustainable Development 6(6):15-33

Wallis, P., O. Flaaten (2003) Fisheries management costs - Concepts and studies. In Schrank, W.E., R. Arnason and R. Hannesson (Eds.) The cost of fisheries management. Ashgate, Hants, Ch. 10

WTO (2010) World Trade Report 2010: trade in natural resources. Available via http://www.wto.org/english/res_e/publications_e/wtr10_e.htm. Cited 15 October 2012, World Trade Organization, Rome 